\title{
A INCLUSÃO NO ENSINO SUPERIOR A PARTIR DA PERSPECTIVA DO SUJEITO
}

\author{
INCLUSION IN HIGHER EDUCATION FROM THE PERSPECTIVE OF THE SUBJECT
}

LA INCLUSIÓN EN LA ENSEÑANZA SUPERIOR DESDE LA PERSPECTIVA DEL SUJETO

\author{
Aline Gomes da Silva \\ Graduada em Pedagogia da Universidade La Salle Canoas. E-mail: aline.gomesylva@gmail.com \\ Hildegard Susana Jung
Doutora em Educação. Universidade La Salle Canoas. E-mail: hildegard.jung@unilasalle.edu.br
}

Louise de Quadros da Silva

Mestranda em Educação na Universidade La Salle Canoas. Bolsista CAPES/PROSUP. E-mail: louise.quadrosdasilva@gmail.com

\begin{abstract}
RESUMO
Este artigo versa sobre o tema da inclusão no ensino superior. Seu objetivo consiste em suscitar um debate referente à autonomia e acessibilidade de estudantes inclusivos de uma universidade da região metropolitana de Porto Alegre, a partir da perspectiva do educando. Para tal, realizamos um estudo de caso, de cunho qualitativo, apoiado em uma revisão de literatura. Além disso aplicamos um questionário a estudantes com deficiência da instituição pesquisada. Os resultados desta revisão apontam para: a) a importância do acompanhamento do aluno incluso; b) os materiais e recursos devem ser adaptados às necessidades de cada estudante; c) a educação inclusiva deve preparar o educando para o mercado de trabalho. Como considerações finais, indicamos que a educação inclusiva é aquela que promove o desenvolvimento pleno do estudante e não possibilita apenas o convívio social.
\end{abstract}

Palavras-chave: Educação inclusiva; Ensino superior; Formação do estudante com deficiência.

\begin{abstract}
This article deals with the topic of inclusion in higher education. Its objective is to raise a debate regarding the autonomy and accessibility of inclusive students of a university in the metropolitan region of Porto Alegre, from the perspective of the student. For that purpose, we conducted a qualitative case study, supported by a literature review. In addition, we applied a questionnaire to students with disabilities of the researched institution. The results of this review point to: a) the importance of accompanying the student; $b$ ) the materials and resources must be adapted to the needs of each student; c) inclusive education should prepare the student for the job market. As final considerations, we indicate that inclusive education is one that promotes the full development of the student and not only enables social interaction.
\end{abstract}

Keywords: Inclusive education; Higher education; Training of students with disabilities.

\section{RESUMEN}

Este artículo versa sobre el tema de la inclusión en la enseñanza superior. Su objetivo consiste en suscitar un debate referente a la autonomía y accesibilidad de estudiantes con discapacidades de una universidad de la región metropolitana de Porto Alegre, a partir de la perspectiva del estudiante. Para ello, realizamos un estudio de caso, de tipo cualitativo, apoyado en una revisión de literatura. Además, aplicamos un cuestionario a estudiantes con discapacidades de la institución investigada. Los resultados de esta revisión señalan a: a) la importancia del acompañamiento del alumno inclusivo; b) los materiales y recursos se deben adaptar a las necesidades de cada estudiante; c) la educación inclusiva debe preparar al estudiante para el mercado laboral. Concluimos que la educación inclusiva es aquella que promueve el pleno desarrollo del estudiante y no posibilita solo el convivo social. 
Palabras-clave: Educación inclusiva; Enseñanza superior; Formación del estudiante con discapacidades.

\section{INTRODUÇÃO}

O estímulo e a melhoria dos processos de aprendizagem e desenvolvimento humano é o núcleo orientador dos diferentes espaços educativos. Nesse sentido buscamos expandir nosso conhecimento sobre a autonomia e acessibilidade de estudantes inclusivos de uma universidade da região metropolitana de Porto Alegre.

Na Educação Superior apenas 0,45\% do total de 8 milhões de matrículas são de alunos com deficiência. A fonte dos dados é o censo da Educação Superior de 2015 (MEC, 2016) em que a evasão entre os estudantes com deficiência é de $27 \%$, sendo maior na rede privada: $31,5 \%$. A deficiência física é a mais comum entre os matriculados e atinge mais de 12,7 mil pessoas inscritas. Depois disso, vêm baixa visão (11 mil alunos), deficiência auditiva (5 mil) e cegueira (2 mil) (BRASIL, 2016).

De acordo com Sassaki (1997) e Paula (2015), é preciso que as escolas tenham uma visão inclusiva, para que possam combater atitudes discriminatórias, acolher a todos os estudantes e defender o direito à educação. A inclusão social pode ser compreendida como “o processo pelo qual a sociedade se adapta para poder incluir, em seus sistemas sociais gerais, pessoas com necessidades especiais e, simultaneamente, estas se preparam para assumir seus papéis na sociedade" (SASSAKI, 1997, p. 41). Dessa maneira, podemos perceber que a inclusão social consiste em um processo de construção de oportunidades para todos.

Uma educação inclusiva implica na coparticipação de toda a sociedade e deve se alicerçar na reconstrução da prática da democracia e da cidadania. Mantoan (1997, p. 20) entende que a "inclusão é um motivo para que a escola se modernize e os professores aperfeiçoem suas práticas e, assim sendo, a inclusão escolar de pessoas deficientes torna-se uma consequência natural". Neste contexto, o presente artigo tem como objetivo suscitar um debate referente à autonomia e acessibilidade de estudantes inclusivos de uma universidade da região metropolitana de Porto Alegre, a partir da perspectiva do educando. 
A arquitetura da pesquisa segue a seguinte estrutura: após esta introdução, apresentamos os percursos metodológicos e, na sequência, a fundamentação teórica. Após, consta a análise e discussão dos achados à luz da teoria e, fechando o estudo, as considerações finais.

\section{Metodologia}

A pesquisa fundamenta-se em analisar a perspectiva do sujeito inclusivo no ensino superior com abordagem qualitativa, pois ela se caracteriza por uma atitude interpretativa e compreensiva (GIL, 2008) sobre a acessibilidade dos alunos inclusos. A coleta de dados ocorreu por meio de revisão de literatura concernente ao tema e a aplicação de um questionário construído por meio do recurso Google Forms, enviado por correio eletrônico, seguindo as orientações de Gil (2008). De acordo com o autor, definimos questionário como uma "técnica de investigação composta por um conjunto de questões que são submetidas a pessoas com o propósito de obter informações sobre conhecimentos, crenças, sentimentos, valores, interesses, expectativas, aspirações, temores, comportamento presente ou passado". (GIL, 2008, p. 121).

O critério de exclusão foi todo aquele que decidiu pela não participação. O critério de inclusão dos participantes foi ser um aluno incluso, portador de alguma deficiência. $O$ total de questionários enviados foi 30 e o número de respostas foi de 10, o que representa uma adesão de 33,33\% à pesquisa. As perguntas enviadas foram: 1) Qual a sua idade em anos?; 2) Qual seu grau de Instrução?; 3) Qual curso faz?; 4) Em que semestre está?; 5) Você tem algum tipo deficiência, transtornos globais do desenvolvimento ou altas habilidades/ superdotação? Qual?; 6) Qual sua opinião sobre o Atendimento Educacional Especializado oferecido pela instituição aos alunos?; 7) Você precisa de acompanhamento em sala de aula? Qual?; 8) Considera importante o acompanhamento em sala de aula? 9) Descreva um pouco sobre a metodologia utilizada em sala de aula pelos seus professores; 10) Os materiais didáticos e avaliações são adaptáveis?; 11) Os recursos utilizados em sala de aula são facilitadores na aprendizagem?; 12) Você se sente preparado para o mercado de trabalho? 
Para nos referirmos aos participantes, os mesmos foram nomeados aleatoriamente com a letra "A" de “Aluno". Além disso, atribuímos números, também de forma aleatória, aos mesmos. Desta maneira, vamos nos referir às respostas dos questionários como pertencentes ao: $A_{1}, A_{2}, A_{3}$ e assim por diante.

A revisão de literatura ocorreu basicamente por meio de livros, artigos científicos e legislação vigente da área educacional. A análise dos dados também recorreu às orientações de Gil (2008) e foi realizada, basicamente, em quatro etapas: a) organização do material e das fontes de busca; b) leitura flutuante, selecionando material pertinente; c) definição da estrutura da pesquisa; c) realização das inferências e registro das mesmas.

\section{Os dispositivos legais da inclusão}

O papel social da educação superior e a necessidade de que transcenda os limites de seu compromisso tradicional com a produção e disseminação do conhecimento se torna discussão na atualidade, sendo destaque em debates acadêmicos. Conforme a Lei Brasileira de Inclusão da Pessoa com Deficiência, nº 13.146 (BRASIL, 2015)

[...] considera-se pessoa com deficiência aquela que tem impedimento de longo prazo de natureza física, mental, intelectual ou sensorial, o qual, em interação com uma ou mais barreiras, pode obstruir sua participação plena e efetiva na sociedade em igualdade de condições com as demais pessoas (BRASIL, 2015).

Verificamos a partir da Constituição da República Federativa do Brasil que a educação é "direito de todos e dever do Estado e da família, será promovida e incentivada com a colaboração da sociedade, visando ao pleno desenvolvimento da pessoa, seu preparo para o exercício da cidadania e sua qualificação para o trabalho" (BRASIL, 1988). Segundo Brasil (2013), podemos dizer que a educação superior se constitui de dois dispositivos legais, prioritariamente: a Lei de Diretrizes e Bases da Educação Nacional (LDB) nº 9394 (BRASIL, 1996) e a Lei n 10.861 (BRASIL, 2004), que trata do Sistema Nacional de Avaliação da Educação Superior (SINAES). A LDB (BRASIL, 1996) em seu capítulo IV, art. 43 explicita como finalidades da educação superior, dentre outras: o incentivo ao espírito científico, formar nas diferentes áreas do conhecimento tornando-os aptos para o mercado de trabalho, vi- 
sar o desenvolvimento da ciência e tecnologia.

Após a implantação da Lei $n^{\circ} 8.213$ (BRASIL, 1991) que fala sobre a contratação de Deficientes nas Empresas, conhecida como a lei de cotas para empresas, questões como acesso, acessibilidade e inclusão tomaram espaço. Em 1994, em Salamanca, realizou-se a Conferência Mundial sobre Necessidades Educacionais Especiais: Acesso e Qualidade, que aprovou o documento Declaração de Salamanca, no qual o Brasil apresentou um compromisso formal. O documento orienta a inclusão de pessoas como meninos de rua, indígenas, pessoas com deficiência, entre outros, como a medida mais eficaz de combate à situação de exclusão. De modo que "Estas escolas devem incluir as crianças com deficiência e as superdotadas, meninos e meninas de rua e crianças trabalhadoras, crianças de origem remotas ou de população nômade, [....]. (UNESCO, 1994, n. p)

Segundo Kassar (1999), o Brasil, no mesmo ano da aprovação da Declaração de Salamanca, passou a assumir o termo "inclusão" no discurso educacional, a partir da elaboração do documento "Tendências e Desafios da Educação Especial”. Elaborado no governo de Itamar Franco, este documento afirma a importância da inclusão na escola comum e da compreensão do conceito inclusão. Com a aprovação da nova Lei de Diretrizes e Base da Educação (BRASIL, 1996), foram estabelecidos princípios para efetivação da matrícula, dos serviços de apoio especializado para atender ás peculiaridades, e da educação para o trabalho, visando a efetiva integração na sociedade.

O decreto $n^{\circ} 3.298$ (BRASIL, 1999) dispõe sobre a Política Nacional para a Integração da Pessoa Portadora de Deficiência e "compreende o conjunto de orientações normativas que objetivam assegurar o pleno exercício dos direitos individuais e sociais das pessoas portadoras de deficiência”. Podemos ainda citar as Diretrizes Curriculares Nacionais para a Educação em Direitos Humanos - Parecer CNE/CP 8/2012, que destaca a responsabilidade das Instituições de Ensino Superior com a formação de cidadãos éticos, comprometidos com a construção da paz, da defesa dos direitos humanos e dos valores da democracia. Outro marco importante é a Lei $n^{\circ} 10.436$ (BRASIL, 2002) que estabelece a língua brasileira de sinais (LIBRAS) como oficial no país juntamente com o Português. Como vimos, no Brasil, a primeira década do século XXI foi fundamental para a afirmação da educação como um 
direito de todos. Dessa forma, a preocupação com a educação das pessoas com deficiência tem como objetivo garantir uma educação de qualidade.

Adequar a Legislação Brasileira às diretrizes de documentos internacionais que defendem a educação inclusiva tem sido um esforço no sentido de fazer cumprir o que já está previsto na Constituição Brasileira. O Decreto n. 5.296/04, que regulamenta as Leis n. 10.048/00 e 10.098/00, estabelece condições para a efetivação da política nacional de acessibilidade. Conforme Garcia e Michels (2011, p. 111),

Ao longo do governo de Luís Inácio Lula da Silva (2003-2010), a Política Nacional de Educação Especial ganhou novos contornos mediante três programas de governo, dois voltados para a Educação Básica e um para a Educação Superior: 1) Programa de Implantação de Salas de Recursos Multifuncionais; 2) Programa Educação Inclusiva: direito à diversidade; 3) Programa Incluir.

Na Educação Superior, o decreto n. 7.611 (BRASIL, 2011) dispõe sobre o Atendimento Educacional Especializado (AEE) que exige a estruturação de núcleos de acessibilidade nas instituições de Ensino Superior, visando eliminar barreiras atitudinais e físicas. Um ano depois, a Convenção sobre os Direitos das Pessoas com Deficiência (CDPD) (2012) assegura um sistema de educação inclusiva em todos os níveis de ensino. Desse modo, pessoas com deficiência não devem ser excluídas do sistema educacional, e devem ter acesso ao ensino fundamental inclusivo, de qualidade e gratuito, de forma igualitária com as demais pessoas na comunidade. No ano seguinte, a Lei Brasileira da Inclusão, n 13.146 (BRASIL, 2015) é “[...] destinada a assegurar e a promover, em condições de igualdade, o exercício dos direitos e das liberdades fundamentais por pessoa com deficiência, visando à sua inclusão social e cidadania.".

A mais recente alteração na legislação sobre pessoas com deficiência, nº 13.409 (BRASIL, 2016), altera a lei de cotas de 2012. Esse marco inclui cotas no ensino superior para pessoas com deficiência, bem como negros, pardos, indígenas e pessoas de baixa renda, oriundos da escola pública.

\section{Os processos de aprendizagem na educação inclusiva}


Promover a inclusão significa uma mudança de postura e de olhar acerca da deficiência, implica quebra de paradigmas, reformulação do nosso sistema de ensino, no qual o acesso, o atendimento adequado e a permanência sejam garantidos a todos os alunos, independentemente de suas diferenças e necessidades. Neste sentido, a educação é uma das principais ferramentas para a transformação social, pois nos dias atuais a desigualdade social e o desrespeito com as diferenças estão cada vez mais em nosso cotidiano, independente de lugares, o que se reflete nas escolas.

Todos têm direito a uma educação igualitária, sem restrições, em que sejamos capazes de buscar alternativas para garantir a inserção de todos na vida social. No Ensino Superior, todo o processo de inclusão educacional tem início com a inserção da inclusão no Plano de Desenvolvimento da Instituição (PDI) e no Projeto Pedagógico dos cursos (PPC).

Faz-se necessário que os conteúdos curriculares e a diversificação metodológica possibilitem aos estudantes uma adequação entre o perfil desejado para a inserção no mercado de trabalho e as características dadas pela especificidade de sua necessidade inclusiva. Observamos que recursos físicos tanto quanto aos mobiliários e materiais didáticos especializados devem estar em consonância com os critérios de acessibilidade dispostos na legislação vigente e as adaptações necessárias deverão acontecer de acordo com matrícula dos alunos.

\section{As relações na educação inclusiva}

No mundo contemporâneo, a inclusão de alunos com deficiência representa um grande desafio. A educação superior vem se ampliando significativamente em consequência do desenvolvimento inclusivo na educação. Com isso, as instituições requerem ter um Núcleo de Atendimento Especializado direcionado a esses perfis de alunos, para um acompanhamento individual aluno/docente. Lira (2014, p. 15) afirma que “[...] entender a diferença presente nos contextos universitários é de fundamental importância, para que posturas inclusivas se construam".

São necessárias adequações e transformações nos espaços escolares, ambientes 
de aprendizagem e nas práticas escolares, materiais para participação do aluno em sala de aula, promovendo os recursos necessários e as intervenções com o uso de novas estratégias para o atendimento com qualidade.

As instituições são um dos principais espaços de convivência social do ser humano durante seu desenvolvimento, formando os alunos para o convívio social, com aprendizagem humanizadora e preparando para o mercado de trabalho. Dessa forma, de acordo com Oliveira, Silva e Costa (2016), o Atendimento Educacional Especializado deve ser organizado e apoiado pelas instituições de ensino, constituindo parte diversificada do currículo dos estudantes da educação especial; algumas atividades ou recursos próprios devem ser utilizados, de acordo com a necessidade.

O art. 208 da Constituição Federal (1988, p. 2) traz como um de seus objetivos: "Promover o bem de todos, sem preconceitos de origem, raça, sexo, cor, idade e quaisquer outras formas de discriminação". Tassinari (2014, p. 8) fala sobre o direito de todos à educação na igualdade de oportunidades de acesso, permanência e o sucesso nesta etapa de ensino.

Neste aspecto devemos assegurar-Ihes o direito à participação assim como às demais pessoas, oportunidades de desenvolvimento pessoal, social e profissional, bem como não restringir sua participação em determinados ambientes e atividades com base na deficiência. Igualmente, a condição de deficiência não deve definir a área de seu interesse profissional. Para que esse contexto seja vislumbrado, os sistemas educacionais precisam tomar para si a responsabilidade de romper com as barreiras às aprendizagens, buscando a sua superação.

\section{Análise e discussão dos dados}

Como anunciado, a pesquisa buscou seus dados, além da análise de literatura, nos questionários enviados pelo Google Drive. O perfil dos participantes da pesquisa aponta que $90 \%$ dos estudantes está na faixa etária de 21 a 30 anos e 10\% na de 31 a 40 anos. O semestre está dividido em $60 \%$ do $3^{\circ}$ ao $6^{\circ}$ semestre e $40 \%$ nos demais. Os cursos de gradua- 
ção são: Produção Multimídia, Pedagogia, Marketing, Gestão de Recursos Humanos e Pós em Graduação de Gestão de Pessoas.

\section{A importância do acompanhamento em sala de aula}

A pergunta relacionada ao acompanhamento dos alunos inclusos em sala de aula foi a seguinte: Considera importante o acompanhamento em sala de aula? Como respostas, obtivemos $90 \%$ dos participantes que consideraram importante este acompanhamento.

Neste sentido encontramos respaldo em Franco (2017), autor que considera o acompanhamento em sala de aula, um dos recursos do Atendimento Educacional Especializado, como potencializador de ações que complementam a inclusão, na medida em que promove a autonomia e participação dos alunos inclusivos. Nas palavras do autor: "O Atendimento Educacional Especializado amplia as habilidades dos alunos, interferindo positivamente no desenvolvimento" (FRANCO, 2017, p. 114).

A partir dos achados, podemos inferir que o acompanhamento em sala de aula é de suma importância e fundamental para a execução do trabalho de inclusão, pois algumas deficiências requerem, por exemplo, o intérprete de libras; muitas das atividades podem ser ofertadas como monitorias, proporcionando meios que estimulem o aluno a aprender.

\section{Materiais e Recursos}

Concernente ao questionamento: Os recursos utilizados em sala de aula são facilitadores da aprendizagem?, chamam a atenção as respostas de alguns participantes, como, por exemplo, A1: "Sim em parte, pois na utilização de recursos como apresentações e vídeos faltam adaptações como áudio, descrição e caixa de libras para facilitar o aprendizado dos alunos".

Por outro lado, está o depoimento de A6: “Não. Percebo que os professores não têm informação suficiente de como trabalhar com surdos". De modo geral, todos os estudantes consideraram necessária a adaptação dos materiais e recursos de tecnologias 
assistivas. Da mesma forma como argumentam Damasceno e Filho (2002), seria uma maneira concreta de neutralizar as barreiras e inserir o indivíduo nos ambientes ricos para a aprendizagem, proporcionados pela cultura.

Podemos observar os Recursos de tecnologias assistivas disponíveis às pessoas com deficiência, conforme dados registrados no Censo 2015 pela Coordenação dos cursos e Graduação da Instituição, de acordo com o Quadro 1.

Quadro 1: Recursos de tecnologias assistivas disponíveis às pessoas com deficiência

\begin{tabular}{|l|}
\hline Guia intérprete \\
\hline Material didático digital acessível \\
\hline Material didático em formato impresso acessível \\
\hline Material em áudio \\
\hline Material em Braile \\
\hline Material em formato impresso em caractere ampliado \\
\hline Material pedagógico tátil \\
\hline Recursos de acessibilidade à comunicação \\
\hline Recursos de informática acessível \\
\hline Tradutor e intérprete de língua brasileira de sinais \\
\hline
\end{tabular}

Fonte: Elaborado pela autora a partir de dados da pesquisa, 2018

Portanto, o uso destes recursos no atendimento educacional de estudantes com deficiência, mobilidade reduzida ou necessidades educacionais especiais favorece uma maior independência, qualidade de vida e, consequentemente, inclusão educacional e social.

\section{Mercado de Trabalho}

Sobre a pergunta: você se sente preparado para o mercado de trabalho? A resposta do participante, A6 foi enfática: “Sim! É necessário muito esforço”. De modo geral, os alunos se sentem preparados para o mercado de trabalho.

Neste sentido, a Constituição Federal de 1988 e o Decreto nº 3.298 (BRASIL, 1999) dispõem sobre a reserva de vagas no mercado de trabalho para pessoas com deficiência, que podem ser compreendidos como principais dispositivos legais que asseguram o direito de acesso ao mercado de trabalho.

Ao definir a "empresa inclusiva”, Sassaki (1997, p. 90) propõe: 


\begin{abstract}
Como sendo aquela que contempla as diferenças individuais, acredita no valor da diversidade humana e promove mudanças internas, tanto físicas como administrativas, garantindo aos funcionários com deficiência a possibilidade de exercerem sua função com qualidade e autonomia. Sendo assim, para o autor a empresa inclusiva deve promover: a) adaptação dos locais de trabalho; b) adoção de esquemas flexíveis no horário de trabalho; c) revisão das políticas de contratação de pessoal; d) revisão dos programas de treinamento e desenvolvimento de recursos humanos; e) palestras que desmistifiquem a deficiência como incapacitante, dentre outras condições.
\end{abstract}

Assim, uma sociedade inclusiva deve propiciar condições de trabalho para todos, não admitindo preconceitos e descriminações, oferecendo variados serviços especializados para atender todas as especificidades das pessoas inclusivas.

\title{
CONSIDERAÇÕES FINAIS
}

Garantir a aprendizagem e o conhecimento das habilidades necessárias para a vida em sociedade com uma educação igualitária para todos e com qualidade, por meio da Educação Inclusiva, -com respeito às diferenças, culturais, sociais, ética e morais-, requer pensarmos a diversidade.

Entendemos que uma aula inclusiva é aquela que promove o desenvolvimento do seu aluno e não apenas favorece o desenvolvimento da convivência social. Muitas vezes, as instituições, ao receberem um aluno inclusivo que se matricula, acreditam que, pelo simples fato de recebê-lo, isto representa a inclusão, quando de fato não é desta forma que este ato pode ser intitulado.

Com a conclusão da pesquisa, podemos perceber, como referimos anteriormente, que para haver a inclusão é necessário que haja aprendizado e participação social, favorecer o desenvolvimento de todos os alunos, e que a Instituição seja um espaço significativo de aprendizagem. Desta maneira sim, poderemos dizer que está sendo desenvolvida a prática inclusiva.

Esperamos que o estudo que ora concluímos, mas que não se esgota aqui, possa suscitar novas pesquisas na área da educação inclusiva, talvez abordando boas práticas de 
inclusão de fato e não somente de direito.

\section{REFERÊNCIAS}

BRASIL. Constituição da República Federativa do Brasil Brasília. Congresso Nacional. Senado Federal, 1988.

. Lei $\mathrm{n}^{\circ}$ 8.213, de 24 de julho de 1991. Lei cotas para Deficientes e Pessoas com Deficiência. Brasília, DF, 1991.

. Política Nacional de Educação Especial na Perspectiva da Educação Inclusiva. Mi-

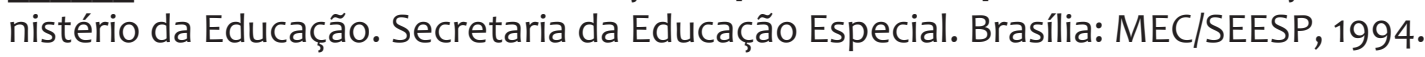

. Lei n. 9.394/1996. Lei das Diretrizes e Bases da Educação Nacional - LDBEN. Diário Oficial da República Federativa. Brasília, 1996.

. Decreto $\mathrm{n}^{\circ}$ 3.298, de 20 de dezembro de 1999. Política Nacional para a Integração da Pessoa Portadora de Deficiência, Brasília, DF, 1999.

. Lei $\mathbf{n}^{\circ}$ 10.436, de 24 de abril de 2002. Dispõe sobre a Língua Brasileira de Sinais Libras e dá outras providências. Brasília, DF, 2002.

. Referências de Acessibilidade na Educação Superior e a Avaliação In Loco do Sistema Nacional de Avaliação da Educação Superior (SINAES). Secretaria de Educação Fundamental. Brasília, 2013.

. Lei n. 13.146, de 6 de julho de 2015. Lei Brasileira de Inclusão de Pessoas com deficiência. Brasília, DF, 2015.

. Lei $\mathbf{n}^{\circ} \mathbf{1 3 . 4 0 9}$, de 28 de dezembro de 2016. Lei de Cotas de Ingresso nas Universidades. Brasília, DF, 2016.

CALDERÓN, Adolfo Ignacio. Responsabilidade Social: desafios à gestão universitária. Revista da Associação Brasileira de Mantenedoras de Ensino Superior, n. 34, v. 23, 2005.

CONVENÇÃO SOBRE OS DIREITOS DAS PESSOAS COM DEFICIÊNCIA. Decreto Legislativo $\mathbf{n}^{\circ}$ 186/2008 - Decreto n 6.949/2009. 4. ed. Brasília: Secretaria de Direitos Humanos, Secretaria Nacional de Promoção dos Direitos da Pessoa com Deficiência, 2012.

FRANCO, Marco Antônio. Práticas Pedagógicas em contextos de Inclusão. $1^{\text {a }}$ ed. São Paulo: Paco Editorial, 2017.

GARCIA, Rosalva Maria C.; MICHELS, Maria Helena. A política de educação especial no Brasil (1991-2011): análise da produção GT15 - Educação Especial da ANPED. Revista Brasileira de Educação Especial, v. 17, p. 105-124, 2011.

GIL, Antônio Carlos. Métodos e técnicas de pesquisa social. 6ª ed. São Paulo: Atlas, 2008. 
KASSAR. Mônica de C. M. Deficiência Múltipla e educação no Brasil: discurso e silencio na história dos sujeitos. Campinas. Autores Associados, 1999.

LIRA, Daiane. Acessibilidade na educação superior: novos desafios para as universidades. In: X ANPED SUL, Florianópolis, 2014.

MANTOAN, Maria Teresa Eglér. A Integração de pessoas com deficiência: contribuições para uma reflexão sobre o tema. São Paulo: Memnon, 1997.

MENDES, Eunicéia Gonçalves. Revista Brasileira da educação. A Radicalização do Debate sobre Inclusão escolar no Brasil. Rio de Janeiro, v. 11, n. 33, p. 387-405, 2006.

MEC. Censo da Educação Superior 2015. Brasília: Ministério da Educação, 2016.

OLIVEIRA, Évila Ferreira de; SILVA, Lidiane Oliveira; COSTA, Lígia Graziela da Silva. Literatura e educação especial. Journal of Research in Special Educational Needs, v. 16, p. 693695, 2016.

PAULA, Alessandra de et al. Inclusão na escola do sistema regular-integração: formação profissional, currículo e família. Revista Intersaberes, v. 10, n. 19, p. 126-141, 2015.

SASSAKI, Romeu K. Inclusão: construindo uma sociedade para todos. Rio de Janeiro: WVA, 1997.

TASSINARI, Ana. Inclusão na educação superior: o núcleo de acessibilidade do claretiano. Rede de educação Batatais, 2014.

UNESCO. Declaração Mundial Sobre Educação para Todos. Tailândia, 1994.

Recebido em: 17/03/2019

Parecer em: 25/03/2019

Aprovado em: 17/04/2019 